\title{
Las herramientas digitales en la enseñanza de español como lengua extranjera: adaptaciones para la ERE en NELE / UFRGS
}

\author{
As ferramentas digitais no ensino de espanhol como língua estrangeira: \\ adaptações para o ERE no NELE/UFRGS
}

Francyelle Viana da Rosa ${ }^{1}$

Monica Mariño Rodríguez²

\begin{abstract}
Resumen
En el presente trabajo tenemos como objetivo exponer y discutir una experiencia de enseñanza de lengua española como lengua extranjera en la modalidad de la Enseñanza Remota Emergencial (ERE), dentro del contexto del Núcleo de Ensino de Línguas em Extensão da Universidade Federal do Rio Grande do Sul (NELE/UFRGS). Para ello, contextualizamos la importancia y la actuación de NELE/UFRGS en la enseñanza de lenguas extranjeras a la comunidad interna y externa de UFRGS y en la complementación de la formación docente de los estudiantes de Letras en dicha universidad. Luego,elucidamos el concepto de ERE, con base en las definiciones de Joye, Moreira y Rocha (2020), y lo que comprendemos como enfoque comunicativo, apoyándonos en el Marco Común Europeo (INSTITUTO CERVANTES, 2001) y en los aportes de Sánchez (2009) y Bajtín (1999). Por fin, buscamos identificar posibilidades de adaptaciones de clases anteriormente previstas para que fueran impartidas presencialmente hacia la ERE, así como señalar herramientas disponibles en línea que puedan auxiliar en la promoción de una clase interactiva que atienda las necesidades del enfoque comunicativo.
\end{abstract}

Palabras clave: Herramientas Digitales. Español como Lengua Extranjera. Enseñanza Remota Emergencial.

\section{Resumo}

No presente trabalho temos como objetivo relatar e discutir uma experiência de ensino em língua espanhola como língua estrangeira na modalidade do Ensino Remoto Emergencial (ERE), dentro do contexto do Núcleo de Ensino de Línguas em Extensão da Universidade Federal do Rio Grande do Sul (NELE/UFRGS). Para tanto, contextualizamos a importância e atuação do NELE/UFRGS no ensino de línguas estrangeiras para a comunidade interna e externa da UFRGS e na complementação da formação docente dos estudantes de Letras desta universidade. Em seguida, elucidamos o conceito de ERE, com base nas definições de Joye, Moreira e Rocha (2020), e o que compreendemos como enfoque comunicativo, apoiando-nos no Marco Comum Europeu (INSTITUTO CERVANTES, 2001) e nas contribuições de Sánchez (2009) e Bajtín (1999). Por fim, procuramos identificar possibilidades de adaptações de aulas anteriormente previstas para o contexto presencial para o ERE, assim como destacar ferramentas disponíveis online que possam auxiliar na promoção de uma aula interativa que atenda às necessidades do enfoque comunicativo.

Palavras-chave: Ferramentas Digitais. Espanhol como Língua Estrangeira. Ensino Remoto Emergencial.

\section{Introducción}

La pandemia de COVID-19 sorprendió a todo el mundo en el año de 2020, exigió distanciamiento social y ocasionó, por consiguiente, grandes cambios en todos los ámbitos de la vida en sociedad: laboral, educacional y personal. Este artículo se produjo, por lo tanto, en un contexto atípico, que exige de los

\footnotetext{
1 Graduanda em Letras. Universidade Federal do Rio Grande do Sul, Porto Alegre, RS, Brasil. Orcid: https://orcid.org/00000002-4178-6121 E-mail: francyellevrosa@hotmail.com.

${ }_{2}^{2}$ Doutora em Letras. Universidade Federal do Rio Grande do Sul, Porto Alegre, RS, Brasil. Orcid: https://orcid.org/0000-00016964-1103 E-mail: monica.narino@gmail.com.
}

LínguaTec, Instituto Federal de Educação, Ciência e Tecnologia do Rio Grande do Sul, Bento Gonçalves 
científicos una búsqueda por soluciones y adaptaciones a esta nueva realidad global. La enseñanza de lenguas extranjeras no está aparte de ese de ese escenario, llevando nuevos retos a los profesionales que actúan en este ámbito educativo.

De esa manera, el objetivo principal de ese escrito es exponer y discutir una experiencia de enseñanza de lengua española como lengua extranjera en la modalidad de la Enseñanza Remota Emergencial (ERE). Buscamos, para tanto, identificar posibilidades de adaptaciones de clases anteriormente previstas para que fueran impartidas presencialmente hacia la ERE, así como señalar herramientas disponibles en línea que puedan auxiliar en la promoción de una clase interactiva que atienda las necesidades del enfoque comunicativo.

De esta manera, en el próximo apartado hacemos una contextualización sobre el Núcleo de Ensino de Línguas em Extensão de la Universidade Federal do Rio Grande do Sul (NELE/UFRGS), proyecto en cual se desarrolló la experiencia de enseñanza comentada aquí, y sobre las modificaciones ocasionadas en la institución en consecuencia de la pandemia. Luego, en el punto tres, buscamos definir los conceptos de ERE y de enfoque comunicativo, ideas centrales de la discusión realizada en este artículo. En la cuarta sección nos dedicamos a relatar los retos y las soluciones encontradas en la práctica de enseñanza llevada a cabo en el año de 2020. En el siguiente apartado, hacemos algunas indicaciones y sugerencias en cuanto la utilización de determinadas herramientas digitales. Y, por fin, realizamos algunas reflexiones finales sobre el empleo de las herramientas en línea en las clases remotas.

\section{EI NELE/UFRGS y la pandemia}

EI NELE/UFRGS es un proyecto de extensión que proporciona a la comunidad académica y no académica cursos libres de idiomas en nueve lenguas distintas: alemán, español, francés, griego, inglés, italiano, japonés, latín y ruso. Además, el Núcleo también ofrece la oportunidad de que los estudiantes del profesorado en Letras de la universidad (alumnos del grado y del pos-grado) desarrollen sus primeras prácticas de enseñanza en lengua extranjera, así como realicen observaciones e investigaciones académicas relacionadas a ellas.

Creado en el año 2000 , el proyecto es organizado por una coordinación general y cada uno de los idiomas dispone de coordinadores específicos, todos docentes de UFRGS, quienes direccionan el trabajo pedagógico de los estudiantes becarios responsables por impartir las clases. Así pues, se puede asegurar que NELE/UFRGS cumple una función indiscutible en la carrera de Letras de la institución. Aunque sea una actividad de extensión, se consigue igualmente agregar los otros dos elementos fundamentales de la estructura universitaria: la enseñanza y la investigación. La primera porque genera 
diálogos entre la teoría y la práctica, ya que los estudiantes de letras pueden aplicar las teorías y metodologías de enseñanza que estudian en el grado, sob la orientación de los profesores de lenguas de la carrera de Letras que coordinan los cursos en NELE. La segunda porque ofrece condiciones para el avance de estudios académicos relacionados a la enseñanza y al aprendizaje de lenguas extranjeras.

El curso de lengua española posee una duración de ocho semestres y está organizado de acuerdo con los niveles propuestos por el Marco Común Europeo de Referencia para las Lenguas (MCER) (INSTITUTO CERVANTES, 2001), ya que es el principal documento de orientación para la enseñanza y el aprendizaje de lenguas y establece criterios seguidos por los más conceptuados exámenes de proficiencia en el mundo. Pedagógicamente el enfoque adoptado es el comunicativo, con el objetivo específico de llevar a los discentes a expresarse en lengua española por medio de la oralidad y de la escritura, así como a conocer manifestaciones culturales de distintos países hispánicos. ${ }^{3}$ De esa manera, en todas las clases, desde el primer nivel, se busca abarcar las cuatro habilidades (comprensión lectora, escritura, comprensión auditiva y habla) por medio de textos, videos, canciones, juegos, dinámicas en grupo y mucha conversación. A partir de eso, es posible entender por qué el año de 2020 y la pandemia del coronavirus trajeron tantos desafíos para la enseñanza y aprendizaje de lenguas en contextos como el del NELE. ¿Cómo promover la interacción, que es la base de una clase de lengua con enfoque comunicativo, sin que haya contacto entre el alumnado en el salón de clase? La respuesta más inmediata y ampliamente difundida a lo largo del año fue la comunicación por medios virtuales. Sin embargo, esta respuesta es seguida por una nueva pregunta: ¿cómo adaptar clases inicialmente presenciales y que buscan sobre todo la interacción al contexto virtual de la ERE?

Las clases de NELE/UFRGS pasaron por ese complejo proceso de transposición de su estructura, administrativa y pedagógica, para ambientes virtuales. La universidad, a la cual se vincula el proyecto, suspendió sus actividades el día 16 de marzo de 2020 sin previsión de regreso. De esta manera, así como ocurrió con todas las acciones académicas de la institución, la coordinación del Núcleo decidió implantar la ERE en el proyecto.

Para que esto pudiera efectuarse de la mejor manera posible, fueron organizados encuentros de formaciones online antes de que empezaran las clases, con el objetivo de presentar algunas herramientas digitales básicas de manera a capacitar a los profesores de todas las lenguas de NELE/UFRGS para este periodo emergencial. Las formaciones fueron impartidas por la profesora de inglés Paula Bellé Ganzer en cuatro encuentros virtuales a lo largo del mes de julio con dos horas de

3 Informaciones disponibles en el sitio web de NELE/UFRGS (http://www.ufrgs.br/nele/12.-idiomas/espanhol). 
duración cada uno. Entre los temas estaba la adaptación de los materiales en papel para el digital, las herramientas educacionales de Google y cómo crear presentaciones con diapositivas.

Por lo tanto, en este artículo, intentamos contestar a la pregunta de cómo adecuar las clases del contexto presencial a la ERE de manera a sugerir, con base en las experiencias de enseñanza en un grupo de Español nivel 1 de NELE/UFRGS, no solamente herramientas en línea, sino también estrategias que puedan auxiliar el profesor en ese proceso de adaptación a un contexto emergencial.

\section{La Enseñanza Remota Emergencial y el Enfoque Comunicativo}

La primera cuestión a ser solucionada al hablar de adaptaciones y herramientas para la ERE es entender qué es exactamente esa modalidad, ya que es muy fácilmente confundida con la modalidad de Enseñanza a Distancia (EaD) por la utilización de las tecnologías. La ERE, al contrario de la EaD, no es un tipo de enseñanza consolidado, porque no tiene una legislación propia, tampoco una larga investigación académica sobre sus implicaciones en el aprendizaje. Es una solución temporaria que tiene como intención adecuar las clases que serían presenciales a un contexto de distanciamiento social. Como exponen Joye, Moreira e Rocha (2020, p.14),

en $\mathrm{EaD}$, la docencia es compartida con otros expertos, tales como el designer educacional, los profesores que producen los contenidos, los productores de multimedia, los ilustradores, los gestores de los Ambientes Virtuales de Aprendizaje (AVAs), entre otros. En la educación remota, el profesor, en la mayor parte de las veces, es el responsable por todo, desde la selección de los contenidos, producción de video clases, implementación de clases en AVAs (cuando hay), entre otros. (traducción nuestra) ${ }^{4}$

Es decir, la modalidad EaD dispone de una organización mejor estructurada e involucra otros profesionales en la planificación, elaboración y ejecución de un curso, además del profesor, haciéndose necesario un equipo multidisciplinario. Ya la ERE, fue originada repentinamente y es conducida por profesores que en general están acostumbrados a impartir clases presenciales. Por eso, necesitan adecuarse apresuradamente a una nueva realidad pedagógica. Son profesionales que carecen de condiciones materiales y tecnológicas, como computadoras, acceso apropiado a Internet, plataforma en línea adaptada a los objetivos pedagógicos, etc. Además, en su mayoría, no tuvieron una formación adecuada para actuar en este contexto de enseñanza. De este modo, el tema pasa a ser la adaptación

\footnotetext{
${ }^{4}$ na EaD, a docência é compartilhada com outros especialistas, tais como o designer educacional, os professores conteudistas, os produtores de multimídia, os ilustradores, os gestores de Ambientes Virtuais de Aprendizagem (AVAs), dentre outros. Na educação remota, o professor, na maioria das vezes, o responsável por tudo, desde a seleção de conteúdos, produção de videoaulas, implementação de aulas em AVAs (se houver), dentre outros. (JOYE; MOREIRA; ROCHA, 2020, p.14)
} 
de las estrategias y de los materiales didácticos utilizados en las clases presenciales para ese nuevo escenario.

Como hemos dicho anteriormente, NELE/UFRGS ofreció una formación inicial a sus profesores becarios para que estos pudieran adaptarse de la mejor forma posible a la situación. Aún así, en el caso de la enseñanza de lenguas extranjeras según un enfoque comunicativo, que es discutida en este artículo, hay todavía otros desafíos más específicos que necesitan ser mencionados.

Hablamos acá de enfoque comunicativo de manera más general, ya que entendemos que dentro de este enfoque hay algunas opciones de métodos orientados hacia la comunicación, que pueden ser combinados o alternados en el salón de clase por los profesores con el objetivo de alcanzar los propósitos pedagógicos planteados. Entre ellos, está incluso el propio método comunicativo. Nos basamos, en ese sentido, en la definición de Sánchez (2009, p.108):

Cuando hablamos de enfoque comunicativo hacemos referencia al movimiento pedagógico que orienta su acción docente hacia el aprendizaje de la lengua con fines comunicativos. (...) Dentro del enfoque comunicativo cabe hablar de un método comunicativo, pero en este caso ya se hace referencia a las acciones concretas en que se materializa la acción docente. Naturalmente hay más opciones comunicativas. Y, entre ellas, se puede hablar, por ejemplo, del método por tareas, del método basado en el contenido, etc.

De esta manera, el objetivo final del método y de los profesores que lo aplican es que los estudiantes se comuniquen de manera eficaz en la nueva lengua. Para eso, es necesario más que conocimientos exclusivamente lingüísticos y gramaticales. Según las indicaciones del MCER sobre la competencia comunicativa, ella "comprende varios componentes: el lingüístico, el sociolingüístico y el pragmático" (INSTITUTO CERVANTES, 2001, p. 13, énfasis del autor). O sea, las circunstancias socioculturales en que se usará el idioma (el componente sociolingüístico) y la funcionalidad de sus recursos lingüísticos en la intercomunicación (el componente pragmático) son tan fundamentales cuanto el aprendizaje de destrezas fonológicas, léxicas y sintácticas (el componente lingüístico) (INSTITUTO CERVANTES, 2001).

Con tales competencias en el horizonte, los métodos comunicativos buscan desarrollar las cuatro destrezas por medio de actividades interactivas contextualizadas siempre poniendo más atención al contenido, al intercambio de informaciones, que a la forma. En otros términos, la parte gramatical y de estructura de la lengua está a servicio de la comunicación y es trabajada en clase de acuerdo con las necesidades impuestas por las situaciones comunicativas orales o escritas (SÁNCHEZ, 2009). Así pues, hacer que los alumnos interactúen con el profesor y entre sí es esencial para el desarrollo de las actividades y, por consiguiente, de las competencias comunicativas de esos estudiantes. Un gran reto de trasposición entre las clases presenciales y la ERE. 
Es válido también señalar brevemente lo que entendemos por interacción en este artículo. Se trata de una comunicación recíproca entre dos o más personas, puesto que, como dice el Referencial Curricular do Rio Grande do Sul, "en el uso del lenguaje, los sujetos emplean un repertorio de recursos compartidos y variables para que, juntos, construyan acciones, posicionándose a cada momento frente los valores que los participantes tornan relevantes, lo que constituye la interacción" (RIO GRANDE DO SUL, 2009, p. 42) (traducción nuestra). ${ }^{5}$

Otro rasgo importante del enfoque comunicativo es la defensa de la utilización de materiales auténticos, ya que empleamos la lengua en situaciones concretas de comunicación y, por eso, no se justifica enseñarla de manera desvinculada de la realidad. En ese aspecto, este enfoque comparte con el filósofo ruso Mijaíl Bajtín la idea de que "el uso de la lengua se lleva a cabo en forma de enunciados (orales y escritos) concretos y singulares que pertenecen a los participantes de una u otra esfera de la praxis humana" (BAJTíN, 1999, p.248). ${ }^{6}$ Por lo tanto, si los estudiantes utilizan la lengua para comunicarse en una determinada situación y con un objetivo concreto, como por ejemplo preguntar la dirección de un sitio, leer la carta de un restaurante o rellenar un documento con sus datos personales, en clase necesitan aprenderla para tal fines. Señalamos que lo que llamamos acá de materiales auténticos son los textos escritos, textos orales, videos e imágenes que se produjeron no con objetivos educativos, sino que en la vida cotidiana. La variedad es enorme, desde reportajes, poemas, canciones y películas, hasta los manuales de instrucciones, recetas de platos típicos, cartas de restaurante, informativos, guías turísticas, folletos de supermercados, etc.

No significa que los materiales diseñados para fines exclusivamente pedagógicos no sean importantes e incluso necesarios en algunos momentos. Sin embargo, se hace esencial comprender que en su totalidad "la complejidad lingüística sólo es observable en el uso de la lengua, no en la formalización teórica abstraída de la realidad" (SÁNCHEZ, 2009, p. 109). Por lo tanto, traer componentes que traspasen las paredes (físicas o virtuales) del salón de clase y que demuestren la interlocución entre personas en contextos reales de uso es parte constitutiva de un aula comunicativa de lengua extranjera. En tal caso, la búsqueda por materiales auténticos y diversificados, que representen de manera concreta diferentes situaciones comunicativas y que lleven a la elaboración de actividades contextualizadas, además de interactivas, es una constante en la labor del profesor de lengua extranjera que sigue este enfoque.

\footnotetext{
${ }^{5}$ No uso da linguagem, os sujeitos lançam mão de um repertório de recursos compartilhados e variáveis para, juntos, construírem ações, posicionando-se a cada momento frente a valores que os participantes tornam relevantes, o que constitui a interação (RIO GRANDE DO SUL, 2009, p. 42).

6 Debido a nuestros intereses y a los límites de espacio en este texto, no se pudo expandir la discusión basada en Bajtín. Sin embargo, destacamos otros diálogos más profundizados entre los conceptos de bajtinianos y la enseñanza de lenguas extranjeras que pueden ser encontrados en RIO GRANDE DO SUL (2009); PÁEZ \& ROJAS (2009); ZAYAS (2012).
} 
Es a partir de eso que surge la cuestión principal de cómo impartir clases comunicativas de español en el contexto de la ERE, que lleva también a algunas otras. ¿Cómo traer materiales auténticos a las clases en línea? ¿Cómo reproducir situaciones concretas de comunicación solamente con interacciones vía internet? ¿Qué estrategias podemos utilizar para promover la interacción entre los estudiantes? No tenemos todas las respuestas, ni tenemos la pretensión de tenerlas. Sin embargo, intentamos identificar aquí algunas de esas dificultades por medio de ejemplos de situaciones concretas de enseñanza, para luego sistematizar algunas alternativas que pueden ser utilizadas por los docentes en este escenario.

\section{Los retos y posibles soluciones}

En 2020 todas las clases de NELE/UFRGS fueron planeadas en grupo por el conjunto de profesores becarios que las impartiría en el mismo nivel del curso y con la supervisión de un docente ya graduado designado por la coordinación del proyecto. Nuestro grupo consistía en cinco profesores, todos estudiantes de Español en la carrera Letras. Nos encontrábamos en línea semanalmente para organizar la clase de la semana correspondiente y decidir qué materiales serían necesarios producir para el encuentro. Por lo tanto, todas las actividades acá descritas no son de autoría individual, sino resultado de un trabajo en conjunto.

El grupo, que tiene sus experiencias de enseñanzas compartidas en este escrito, estaba inicialmente formado por 18 estudiantes, de los cuáles 16 siguieron hasta el final de un total de 13 encuentros. La mayoría de ellos eran jóvenes, entre 20 y 30 años de edad, con la excepción de dos mujeres con más de 50 años. Cada clase estaba compuesta por 4 horas/clase de 45 minutos, lo que totalizaron 54 horas/clase al término del curso. Los encuentros ocurrieron todos los sábados, entre los días 08 de agosto y 31 de octubre de 2020 de las 9 a las 12 horas de la mañana por medio de la plataforma Google Meet.

La plataforma de videollamadas de Google fue elegida por el hecho de ofrecer fácil acceso al público del curso, sin que fuera necesario hacer la descarga e instalación de aplicaciones en la computadora, ni registros previos en el sitio web para acceder a las clases. Además, la posibilidad de utilización de un mismo enlace para todos los encuentros también proporcionaba un ingreso más práctico a la plataforma por parte de los estudiantes, teniendo en cuenta que ni todos tenían facilidad en lidiar con las nuevas tecnologías.

Desde el primer día de clases, fue solicitado a los discentes que mantuvieran sus cámaras abiertas a lo largo de todo el encuentro, pero que abrieran sus micrófonos solamente cuando fueran 
hacer alguna intervención en la clase. Esa solicitación fue hecha con el objetivo de evitar interferencias y ruidos innecesarios que podrían dificultar la comprensión de quién estuviera hablando por parte de los demás compañeros. Se esperaba que esa cuestión de los micrófonos pudiera tornarse una de las grandes complicaciones en la adaptación para la enseñanza remota, que dificultaría la interacción entre estudiantes y profesores. Sin embargo, en el caso de este grupo, la preocupación no se confirmó, ya que la mayoría del alumnado siguió las recomendaciones; con la excepción de 3 ó 4 integrantes que algunas veces mantuvieron la cámara cerrada durante gran parte de la clase.

Los desafíos impuestos al profesor, con respecto a intentar que los alumnos introvertidos participaran más activamente de los encuentros presenciales, principalmente de las actividades de conversación, son muy parecidos con los vivenciados en las clases en línea con aquellos que preferían no prender sus cámaras o que se comunicaban solamente cuando cuestionados por el profesor. Es posible hacer una comparación entre el comportamiento de este grupo, con el de aquellos que en las clases presenciales se muestran muy tímidos y con dificultades en hacer actividades colectivamente, interactuar con sus compañeros e incluso sacar dudas. De esa forma, las estrategias utilizadas también fueron muy parecidas: intentar promover algunos trabajos en grupos menores e interactuar con ellos haciendo preguntas o comentarios más específicos y direccionados.

Aunque sea necesario salientar también la existencia de otras cuestiones involucradas en el caso de las cámaras y micrófonos. Tanto de órdenes tecnológicas, como problemas de operatividad de los aparatos y de conexión, cuanto sociales, como el ambiente de estudio en casa, más personas en su entorno, ruidos de los vecinos o familiares, la ropa que se está usando e incluso el deseo de participar de la clase desde la cama. Sin embargo, estos otros factores están más allá del alcance pedagógico del docente.

La dificultad de conexión a Internet fue otra particularidad que esta modalidad de enseñanza trajo. Ya en el primer día, al intentar mostrar un video a los alumnos, estos relataron que no consiguieron comprenderlo porque su audio y imagen estaban trabando. Aunque este problema no haya ocurrido otras veces en actividades con videos en clases siguientes, fue un indicativo de la necesidad de que siempre se tenga un "plan B" para situaciones como esa. Es decir, una actividad que pueda sustituirla caso la mala conexión a Internet imposibilite tareas que involucren audios y videos.

La división de los estudiantes en pequeños grupos por la primera vez también explicitó algunas dificultades. Cada grupo recibió un enlace distinto para que pudieran comunicarse y realizar la actividad propuesta. Sin embargo, como en la plataforma de Google Meet es necesario que el administrador de la llamada acepte a las demás personas para que puedan entrar en la videoconferencia, la profesora tenía 
que estar en todos los enlaces al mismo tiempo. Esto hizo que se sobrecargara la computadora y todas las llamadas fueran cerradas automáticamente. En este día, la solución fue adaptar la actividad para que fuera realizada en el gran grupo. De este modo, el ejercicio fue hecho con todos los discentes en una única videollamada, forma como se desarrolla la mayor parte de la clase.

Para mantener una clase en línea de 3 horas, con 16 alumnos, interactiva y motivadora, aparte de las actividades en grupo, se buscó emplear distintas herramientas en línea para dinamizar el aula: presentaciones con diapositivas, audios, videos de Youtube, actividades interactivas en Jamboard, resolución de ejercicios con edición simultánea entre los compañeros en Google docs y tareas de casa utilizando plataformas como el Padlet y el Live Worksheets.

Aunque todas las clases hayan sido planeadas pensando siempre en simplificar el acceso de los estudiantes, las dos alumnas mayores todavía sentían un poco de dificultad para entrar en algunos enlaces. Ellas demostraban esas limitaciones con la tecnología, principalmente, al intentar hacer cambios de pestañas o ventanas en el navegador, por ejemplo entre la sala de Meet con todo el grupo y la de Hangouts para actividades en tríos o cuartetos. Por eso, identificando esa dificultad, más prominente en una de ellas, fue marcado un encuentro individual con la discente en el que se la auxilió a guardar los principales enlaces utilizados en las clases en los "favoritos" o "marcadores" de su navegador de Internet. De esa manera, ella conseguía cambiar de plataforma de una manera más simplificada, sin que fuera necesario buscar los enlaces para accederlas.

A partir de todas esas dificultades reales, encontradas en la práctica de la enseñanza de español con objetivos comunicativos en el contexto de la ERE, es que pensamos el próximo apartado. La idea es sistematizar sugerencias que puedan auxiliar al profesor, trayendo alternativas de como lidiar con situaciones similares.

\section{Algunas indicaciones y sugerencias}

Después de describir las dificultades impuestas por la pandemia y la ERE para la enseñanza de lenguas extranjeras por medio del enfoque comunicativo, así como relatar algunos retos vividos en situaciones prácticas dentro de ese contexto, buscamos traer las alternativas encontradas como propuestas para otros profesores en este escenario. Por eso, el objetivo principal de este apartado es hacer indicaciones y sugerencias de herramientas en línea, así como de estrategias y posibles actividades para hacer algunas de las adaptaciones exigidas por la modalidad de la ERE.

a) Utilizar diapositivas como un guión para las clases en línea. 
Las diapositivas son una herramienta multifuncional. Ellas pueden ser utilizadas para traer los principales tópicos que serán trabajados en aquel encuentro, exponer textos e imágenes y escribir explicaciones más sencillas. Pero también pueden ser grandes aliadas en el planeamiento y organización de la clase. Aunque la idea sea utilizar otros sitios y plataformas, en las diapositivas se puede organizar el orden de las actividades, creando un hilo que las conecte a lo que se estaba haciendo antes, dejar explicaciones a los discentes de cómo las tareas serán hechas y los enlaces que deberán acceder para realizarlas.

En las actividades en grupo, por ejemplo, se puede hacer el sorteo de los integrantes previamente y exponer el resultado en una diapositiva, juntamente con el enlace que deben adentrar para comunicarse y realizar la tarea. De igual forma, se puede enumerar lo que se hará en la clase, exponer la resolución de un ejercicio o de una tarea de casa, ilustrar con imágenes el vocabulario que se está trabajando, insertar videos de Youtube (para que se pueda exhibir sin abrir nuevas ventanas en el navegador), dar las instrucciones de una evaluación e incluso hacer juegos de pregunta y respuesta 0 de opción múltiple. Aparte de eso, diapositivas coloridas, atractivas y bien ordenadas pueden ayudar a captar y mantener la atención de los estudiantes en la clase. Hay algunas plataformas que pueden auxiliar el profesor en la construcción de eses materiales como el SlidesGo (slidesgo.com), el SlidesCarnival (slidescarnival.com), el Canva (canva.com), entre otros que ofrecen modelos de plantillas ya listas, con opciones de colores e íconos, y que pueden ser añadidas y editadas en Google Slides (docs.google.com/presentation) con facilidad.

b) Utilizar el Live Worksheets como una plataforma de tareas de casa.

Esta es una plataforma que hace que sea posible convertir archivos en pdf en diferentes ejercicios interactivos: respuesta escrita/abierta, opción múltiple, unir con flechas, arrastrar y soltar, ejercicios de escucha, etc. En otras palabras, es una gran herramienta para adaptar aquellas actividades que ya teníamos listas para las clases presenciales, para el ambiente digital. Además, al finalizar la tarea, que el alumno tendrá accedido por medio de un enlace enviado previamente, el podrá comprobar sus respuestas automáticamente o enviarlas al correo electrónico de su profesor.

Es importante señalar que Live Worksheets (es.liveworksheets.com), aunque sea más dinámico como actividad individual, no posibilita la edición de un mismo archivo por más de una persona de forma simultánea como el Google Docs (docs.google.com). Por lo tanto, no es una buena solución para tareas en grupo que serán realizadas en la parte síncrona de la clase, ya que los alumnos no conseguirán construir respuestas en conjunto. Sin embargo, fue una herramienta utilizada con éxito, en las clases de 
NELE/UFRGS relatadas aquí, para disponibilizar los materiales que serían hechos como tarea de casa, siendo que estas eran resueltas individualmente.

c) Hacer devoluciones de las tareas de casa por correo electrónico.

Otra experiencia interesante, que quizá pueda auxiliar otros docentes en la misma situación de ERE, fue hacer las devoluciones de las tareas de casa vía correo electrónico. Sin dudas examinar las actividades hechas por los discentes, identificar dificultades y hacer sugerencias de estudio son herramientas importantes en la enseñanza de lenguas.

Independientemente si las habían hecho en Live Worksheets, en Google Docs o en el propio Word, las tareas al fin eran enviadas por correo electrónico a la profesora y, por eso, pareció lógico contestarlas por medio de la misma plataforma. De esta manera, el profesor tiene la oportunidad de hacer las devoluciones de forma individual, con comentarios personalizados y direccionados a cada estudiante y sus particularidades. También queda facilitado la comunicación entre discente y docente caso haya alguna duda sobre la realización de la tarea o los comentarios y correcciones hechos.

d) Recurrir al Jamboard como una posibilidad de construcción de actividades interactivas simples

Las herramientas ofrecidas por Google, en general, tienen una gran ventaja, que es la de proporcionar la edición simultánea del contenido entre diversas personas. El Jamboard (jamboard.google.com) no es diferente. Fue creado como una "pizarra digital colaborativa" y trae, por lo tanto, la oportunidad de que profesores y alumnos construyan materiales juntos en una pizarra blanca. También es un instrumento muy útil para actividades en grupo, principalmente las que involucran relacionar imágenes y textos, ya que es muy intuitivo y fácil de utilizar.

Entre los elementos disponibles en esta plataforma están el bolígrafo, la goma de borrar, el láser, las notas adhesivas, en las cuales se puede añadir texto, y la posibilidad de agregar imágenes desde la computadora o directo de Internet. Algunos ejemplos de actividades posibles de desarrollarse en esta herramienta en línea son: relacionar determinado vocabulario con imágenes/dibujos, agrupar palabras/imágenes según categorías y ordenar frases o diálogos simples. Además del Jamboard, también hay otras plataformas que ofrecen pizarras digitales, como el NoteBook Cast (notebookcast.com), el ClassroomScreen (classroomscreen.com) y el Explain Everything (explaineverything.com). Sin embargo, ni todas son de edición simultánea y, por disponer de algunos recursos extras, pueden ser un poco más complejas de ser comprendidas y aplicadas en clase.

e) Valerse del Hangouts como alternativa al Google Meet en la división de grupos. 
Como relatado en el apartado anterior, la plataforma de Google Meet (meet.google.com) no posee un recurso específico que posibilite la subdivisión de los estudiantes en pequeños grupos; haciendo que sea necesario abrir nuevos enlaces con nuevas videollamadas para la realización de ese tipo de actividad tan importante para la comunicación e interactividad entre discentes. Para ejecutar ese proceso, el profesor terminaba por tener que abrir todas las salas de videoconferencia y aceptar los integrantes de los grupos en cada una de ellas al mismo tiempo. Lo que además de trabajoso y confuso, puede ocasionar sobrecarga en la red de Internet o en la computadora.

Por eso, la solución encontrada fue utilizar una versión anterior de la plataforma, el Hangouts (hangouts.google.com), que no solicita la liberación de los integrantes para ingresar en la llamada. De esta manera, los alumnos pueden adentrar sin el auxilio inmediato del profesor y este puede entrar y salir de cada una de ellas alternadamente para atenderlos sin que haya interferencia de sonidos o que sobrecargue su computadora.

En el cuadro abajo sistematizamos las herramientas indicadas aquí, así como sugerimos su utilización para la adaptación de algunas actividades que pueden ser útiles en una clase con enfoque comunicativo. Otras herramientas digitales y sugestiones de uso para la enseñanza de lenguas extranjeras pueden ser encontradas en Santos y Ferreira (2020) y Silva et. al. (2020).

\begin{tabular}{|c|c|c|c|}
\hline $\begin{array}{l}\text { Herramientas } \\
\text { digitales }\end{array}$ & $\begin{array}{l}\text { Plataformas en } \\
\text { línea }\end{array}$ & Utilidad & Ejemplos de actividades \\
\hline $\begin{array}{l}\text { Presentaciones } \\
\text { con diapositivas }\end{array}$ & $\begin{array}{c}\text { Google Slides } \\
\text { SlidesGo } \\
\text { SlidesCarnival } \\
\text { Canva }\end{array}$ & $\begin{array}{c}\text { Organización de la clase; } \\
\text { Contextualización de } \\
\text { situaciones comunicativas; } \\
\text { Explicaciones; } \\
\text { Corrección de actividades; } \\
\text { Presentación de textos } \\
\text { sobre temática concretas; } \\
\text { Ilustración de vocabularios; } \\
\text { Incorporación de videos. }\end{array}$ & $\begin{array}{c}\text { Lectura conjunta y en voz } \\
\text { alta en clase; } \\
\text { Debates sobre textos o } \\
\text { videos; } \\
\text { Trabajo con videoclips y } \\
\text { letras de canciones; } \\
\text { Prácticas de pronunciación; } \\
\text { Juegos culturales de } \\
\text { pregunta y respuesta o } \\
\text { opción múltiple; } \\
\text { Construcción de hipótesis } \\
\text { sobre imágenes. }\end{array}$ \\
\hline $\begin{array}{c}\text { Ejercicios } \\
\text { interactivos }\end{array}$ & LiveWorkSheets & $\begin{array}{l}\text { Adaptación de actividades } \\
\text { imprimibles (en pdf) para } \\
\text { ejercicios interactivos como }\end{array}$ & $\begin{array}{c}\text { Comprensión } \\
\text { auditiva/textual; }\end{array}$ \\
\hline
\end{tabular}




\begin{tabular}{|c|c|c|c|}
\hline & & $\begin{array}{l}\text { respuesta abierta; opción } \\
\text { múltiple; unir con flechas y } \\
\text { arrastrar y soltar. }\end{array}$ & $\begin{array}{c}\text { Relacionar imágenes y } \\
\text { vocabulario; } \\
\text { Llenar huecos; } \\
\text { Construir u ordenar } \\
\text { frases/diálogos; } \\
\text { Hacer descripciones físicas } \\
\text { y emocionales. }\end{array}$ \\
\hline $\begin{array}{l}\text { Edición } \\
\text { simultánea de } \\
\text { archivos }\end{array}$ & $\begin{array}{l}\text { Google Docs } \\
\text { Google Slides }\end{array}$ & $\begin{array}{l}\text { Edición de archivos en } \\
\text { grupos grandes o pequeños } \\
\text { de forma simultánea. }\end{array}$ & $\begin{array}{l}\text { Construcción de textos en } \\
\qquad \text { grupo; } \\
\text { Organización de } \\
\text { presentaciones en grupo; } \\
\text { Resolución de ejercicios y } \\
\text { construcciones de } \\
\text { respuestas en grupo. }\end{array}$ \\
\hline $\begin{array}{c}\text { Pizarras } \\
\text { interactivas }\end{array}$ & $\begin{array}{c}\text { Jamboard } \\
\text { NoteBook Cast } \\
\text { Explain } \\
\text { Everything }\end{array}$ & $\begin{array}{c}\text { Utilización como pizarra } \\
\text { para explicación en clase } \\
\text { compartiendo pantalla; } \\
\text { Edición simultánea entre } \\
\text { estudiantes para la } \\
\text { resolución de juegos y } \\
\text { ejercicios. }\end{array}$ & $\begin{array}{c}\text { Relacionar el vocabulario } \\
\text { con imágenes/dibujos } \\
\text { arrastrando y soltando } \\
\text { elementos; } \\
\text { Agrupar/dividir } \\
\text { palabras/imágenes según } \\
\text { categorías; } \\
\text { Ordenar frases o diálogos } \\
\text { simples; } \\
\text { Relacionar personalidades } \\
\text { famosas con sus nombres } \\
\text { y/o profesiones; } \\
\text { Crear un álbum familiar o un } \\
\text { árbol genealógico utilizando } \\
\text { el vocabulario adecuado; } \\
\text { Nombrar las partes de la } \\
\text { casa a partir de una imagen. }\end{array}$ \\
\hline Videollamadas & $\begin{array}{c}\text { Google Meet } \\
\text { Hangouts }\end{array}$ & $\begin{array}{l}\text { Interacción síncrona entre } \\
\text { docente y discentes; } \\
\text { Interacción síncrona entre } \\
\text { estudiantes en pequeños } \\
\text { grupos con observación del }\end{array}$ & $\begin{array}{l}\text { Explicaciones; } \\
\text { Prácticas de pronunciación; } \\
\text { Debates y conversaciones; } \\
\text { Presentaciones orales; }\end{array}$ \\
\hline
\end{tabular}


(de la) profesor(a).

\section{Consideraciones finales}

Ante los desafíos presentados por la pandemia, tuvimos que buscar soluciones que ni siempre fueron de fácil aplicación. Cuando se decidió por la modalidad ERE, surgieron muchas dudas sobre la aplicabilidad de la enseñanza de español a partir de un enfoque comunicativo en este contexto. En aquel momento, el reto principal era garantizar que el aprendizaje de los estudiantes fuera posible. El propósito era que no se perdiera de vista los objetivos trazados pedagógicamente: desarrollar las cuatro destrezas comunicativas, para que los alumnos pudieran expresarse adecuadamente en lengua española y entrar en contacto con las manifestaciones culturales de los distintos países hispánicos.

Las herramientas digitales tuvieron un rol importante al pensarse alternativas que pudieran promover la interacción efectiva entre los alumnos, componente esencial de una clase de lengua extranjera. Para hallarlas y ponerlas en práctica fue necesario ir más allá de los instrumentos educacionales que ya conociamos y utilizábamos cotidianamente. Experimentar esas nuevas alternativas y observar las facilidades y dificultades de sus aplicaciones fue una etapa esencial en esa adaptación que, al ser relatada aquí, busca auxiliar a otros docentes en el transcurso de ese proceso educacional tan específico que estamos viviendo.

\section{Referencias}

BAJTíN, M. El problema de los géneros discursivos. In: Estética de la creación verbal. Décima edición. Ciudad de México: Siglo Veintiuno Editores, 1999. p. 248 - 293.

INSTITUTO CERVANTES. Marco común europeo de referencia para las lenguas: aprendizaje, enseñanza, evaluación. Madrid: MECD-Anaya, 2001. Disponible en: <http://cvc.cervantes.es/ensenanza/biblioteca_ele/marco/>. Accedido en: 15 feb. 2021.

JOYE, C. R.; MOREIRA, M. M.; ROCHA, S. S. D. Educação a Distância ou Atividade Educacional Remota Emergencial: em busca do elo perdido da educação escolar em tempos de COVID-19. Research, Society and Development, v. 9, n. 7, 2020. https://doi.org/10.33448/rsd-v9i7.4299. 
PÁEZ, A. C.; ROJAS, L. S. A. Lenguaje, dialogismo y educación. Revista Folios. Universidad Pedagógica Nacional. Bogotá, Colombia, n. 29, p. 37-50, 2009. Disponible en: $<$ http://www.scielo.org.co/scielo.php?script=sci_arttext\&pid=S0123-48702009000100004 >. Accedido en: 20 abr. 2021.

RIO GRANDE DO SUL. Referencial Curricular do Rio Grande do Sul - Liç̃es do Rio Grande: Linguagens, Códigos e suas Tecnologias. Língua Portuguesa/Língua Estrangeira. Porto Alegre: SEDUC/RS, 2009. Disponible en: 〈https://servicos.educacao.rs.gov.br/dados/refer_curric_vol1.pdf>. Accedido en: 20 abr. 2021.

SÁNCHEZ, A. Métodos orientados hacia la comunicación. In: . La enseñanza de idiomas en los últimos cien años. Madrid: SGEL, 2009. p. 95-165.

SANTOS, C. F.; FERREIRA, C. C. Era multimodal e tecnológica: que recursos utilizar no ensino de línguas estrangeiras/adicionais? LínguaTec, Instituto Federal de Educação, Ciência e Tecnologia do Rio Grande do Sul, Bento Gonçalves, v. 5, n. 2, p. 149-168, 2020. https://doi.org/10.35819/linguatec.v5.n2.4539.

SILVA, A. T; PEREIRA, W. V; OLIVEIRA NETO, F. X; FEITOZA, L. M; SOUZA, F. I. A. O Professor de Línguas Estrangeiras no Ensino Remoto Durante a Pandemia do Coronavírus. Rev. FSA, Teresina, v.17, n. $12, \quad$ art. $15, \quad$ p. 303-323, dez. 2020. Disponible en: <http://www4.unifsa.com.br/revista/index.php/ssa/article/view/2180>. Accedido en: 02 mar. 2021

ZAYAS, F. Los géneros discursivos y la enseñanza de la composición escrita. Revista Ibero-americana de Educação. n. 59 , p. $63-85, \quad 2012$. Disponible en: $<$ https://rieoei.org/historico/documentos/rie59a03.pdf>. Accedido en: $20 \mathrm{abr} 2021$.

Data de submissão: 15/03/2021. Data de aprovação: 22/04/2021. 